\title{
Reaching the Impossible: Tales of a Computer Graphics Teacher
} Sicilia Ferreira Ponce Pasini Judice

Faculty of Technical Education of the State of Rio de Janeiro, Brazil

\section{Abstract}

I taught computer graphics from 2009 to 2018 in a public college of the state of Rio de Janeiro, in Brazil, in a beautiful city called Petropolis. This college offers a course called Training in Information and Communication Technology, with 3 years of duration, divided into 6 terms. My discipline of Introduction of Computer Graphics occurs in the 4th term where normally students are worried about getting a job or retaining the job they already have. In Brazil we don't have many job opportunities in computer graphics, although this market has been growing in recent decades. That being sad, my discipline was not that attractive as I would like it to be. In this article I'm going to talk about how computer graphics have motivated students to improve their programming skills, even though they are not interested in it. Furthermore, I'm going to present some success stories from students who are effectively working with computer graphics.

\section{Publication History:}

Received: May 20, 2020

Accepted: June 20, 2020

Published: June 22, 2020

\section{Keywords:}

Cloud Computing, PHR, CHR, IaaS, PaaS, SaaS, Models of Cloud Computing,

\section{Introduction}

First of all, who am I? Letting the philosophical implications aside, I am a 36 years old female Brazilian living nowadays in the city of Calgary, in Canada. I am doing a post doctorate in computer science at University of Calgary. I am researching about sketch-based modeling techniques for visualization in oil and gas industry.

But let me go back in time a little bit. I was born in a city called Campos dos Goytacazes, in Rio de Janeiro state, Brazil. My father is a dentist and my mother worked as a teacher until she retired, and none of them have knowledge about technology. The city's economy is based on oil extraction, which made my parents wish me to work in this area [1]. I grew up listening my mother complaining about the life of a teacher and my father's concerned about how expensive is to maintain a proper environment to work as a dentist. So, I quickly learned that a frustrating work environment produces an unbalanced family environment. Which made me decide that whatever the profession I should choose something that motivated me.

Back in 2000, during high school I had the opportunity to attend a technical course about computation. It was my first contact with computers. I learned programming using Pascal language and I still remember how I felt when I wrote my first Hello World code, it was an unique experience. But what really called my attention was the visual aspect, the ability of manipulate colors in order to create an image. I and some curious friends decided to make an animation just by moving colors on the screen, and until now I use to say that it was love at first pixel.

In 2002 I enrolled in a computer science college, motivated to know more about computer graphics. During college I had the opportunity to participate in a scientific initiation project about Computational Simulation of Temperature Distribution in Processes under High Pressures and Temperatures. In this project I was responsible for the implementation of the entire simulator, using Object Pascal as programming language. It was my first contact with scientific research and this work resulted in 4 publications [2]. That was the moment when I realized that I wanted to work with computer graphics specifically for scientific research.

\section{Teaching Environment}

In 2007 I moved to a city called Petropolis, in Rio de Janeiro state, in order to achieve a master's degree in computational modeling at
LNCC (National Laboratory of Scientific Computing) [3] (Figure 1). I studied animation of fluids for computer graphics applications using a LGCA method called FHP and a LBM method called D2Q9, both two-dimensional models. I proposed 3D fluid animation techniques based on the FHP and D2Q9 as well as interpolation methods. In 2010 I started my $\mathrm{PhD}$ research at LNCC developing a methodology involving two-dimensional fluids initialization through sketching techniques along with diffusion-reaction equations and fluid simulation using Lattice Boltzmann Method (LBM) [2].

In 2009, when I was finishing my master's degree, I had the opportunity to become a teacher at FAETERJ (College of Technical Education of the State of Rio de Janeiro) [4] (Figure 1), a public college in Petropolis that is located alongside LNCC. I was hired specifically for teaching computer graphics. This college offers a course called Training in Information and Communication Technology, with 3 years of duration, divided into 6 terms. My discipline of Introduction of Computer Graphics occurs in the 4th term where normally students are worried about getting a job or retaining the job they already have. In Brazil we don't have many job opportunities in computer graphics, although this market has been growing in recent decades. This is why my discipline was not that attractive as I would like it to be.

The college aims to prepare the student for the job market. The city of Petropolis has received many technology companies which makes the demand for more specialized labor increase. Job opportunities include systems developer, technical support and database analyst. FAETERJ is the only public college of technical education at Petropolis and it is responsible for providing nearly $70 \%$ of the technology workforce in the region. Meantime, for being located next to a research lab, many faculty members are also researchers, as was my case. This has created an interesting effect on students. Many began to take an interest in the area of research, some of them did masters and doctorates, and today they work as researchers and professors in universities.

"Corresponding Author: Dr. Sicilia Ferreira Ponce Pasini Judice, Faculty of Technical Education of the State of Rio de Janeiro, Brazil; E-mail: siciliajudice@gmail.com

Citation: Judice SF (2020) Reaching the Impossible: Tales of a Computer Graphics Teacher. Int J Comput Softw Eng 5: 156. doi: https://doi.org/10.15344/2456$4451 / 2020 / 156$

Copyright: (c) 2020 Kuppuswamy et al. This is an open-access article distributed under the terms of the Creative Commons Attribution License, which permits unrestricted use, distribution, and reproduction in any medium, provided the original author and source are credited. 
Other students realized that they could work with computer graphics if they wanted, even though it seems like something impossible to happen. I say impossible because our structure did not allow to develop very elaborated works. Because it is a public college, we depend on the government's money to pay the bills and buy the necessary equipment. The money destined for education in Brazil has always been very restricted, and in the last years it has decreased due to the economic crisis that the country is facing in the midst of cases of corruption. Using only government money, we could barely pay the college bills. But because of a huge dedication effort from faculty members, we were able to set up several labs with donated computers. These machines are usually older, which makes it difficult to explore interesting works in computer graphics. Nevertheless, where there's a will there's a way!

\section{Methodology}

When I started to teach I had no idea how to do it. So I prepared some slides talking about the theory behind computer graphics. Basically I would explain the topic for two hours and only at the end I would show some practical examples. And I would provide the source code so that the students could play with it at their homes. Besides that, in order to evaluate their progress, I would prepare theoretical exams where they would test their knowledge. The result achieved in these exams would determine the success rate in the discipline.

In my first year as a teacher I was frustrated because many students couldn't achieve enough grade to pass and because I could tell that they weren't enjoying to learn something that motivates me so much. I couldn't understand how they could not enjoy something so visual, so interesting. It was then that a student asked me the following question: what do I need to know minimally to pass in computer graphics? And he continued: I only ask this because I have no interest in working in this area. And just like this I understood what was going on: I was treating the computer graphics class in an isolated way, ignoring the history of the students, their reality, the purpose of the college and the career goals. Therefore, I analyzed the methodology that was being used and highlighted the following problems:

1. Two hours talking about theory is too much and the students lose concentration quickly.
2. Practical examples are the best part because it is when the students can see the magic happening. More than that, they can manipulate and create something by their own. And it was not being well used during class.

3. Letting the practice to be done at home is a risk, because when we try to do something new and we fail, we are prone to give up. In addition, not all students have computers at home.

4. Theoretical examinations are by themselves exhausting. Having to study a subject that the student does not deem important for his career makes the exam even more painful.

Once analyzing the weaknesses of the methodology I was able to create a new teaching environment. My main concern was to make this environment as productive as possible for all students, regardless of whether they pursue a career in computer graphics or not. In my discipline we used $\mathrm{C} / \mathrm{C}++$ Programming Language with OpenGL library for the implementation and I realized that most of the students had difficulty in programming. So I started using most of the class time in implementation. Basically I started the class with some theoretical explanation, but no more then 20 minutes, and I used the rest of the time motivating the student to implement what they have learned. It could be done in group or alone, but each one of them had to understand what they were doing. And I was available all the time to discuss about any kind of doubts.

This change requires a little more patience from the teacher. It is common for the same doubt to arise several times, or to have to explain again the theoretical content. Therefore, it is important to exercise empathy. In order for the student to take advantage of this methodology, he must first feel safe to talk about his doubts. In a class full of different students we will have advanced doubts as very basic one. It is extremely important to treat all of them with the same level of importance. In this scenario, the students started to learn more about programming because they felt safe to ask everything they didn't know or didn't understand well. Thus, even that student who was not interested in computer graphics began to take an interest in the exchange of knowledge. And even more interestingly, they began to develop a behavior of helping each other, transforming the class in a very productive environment.
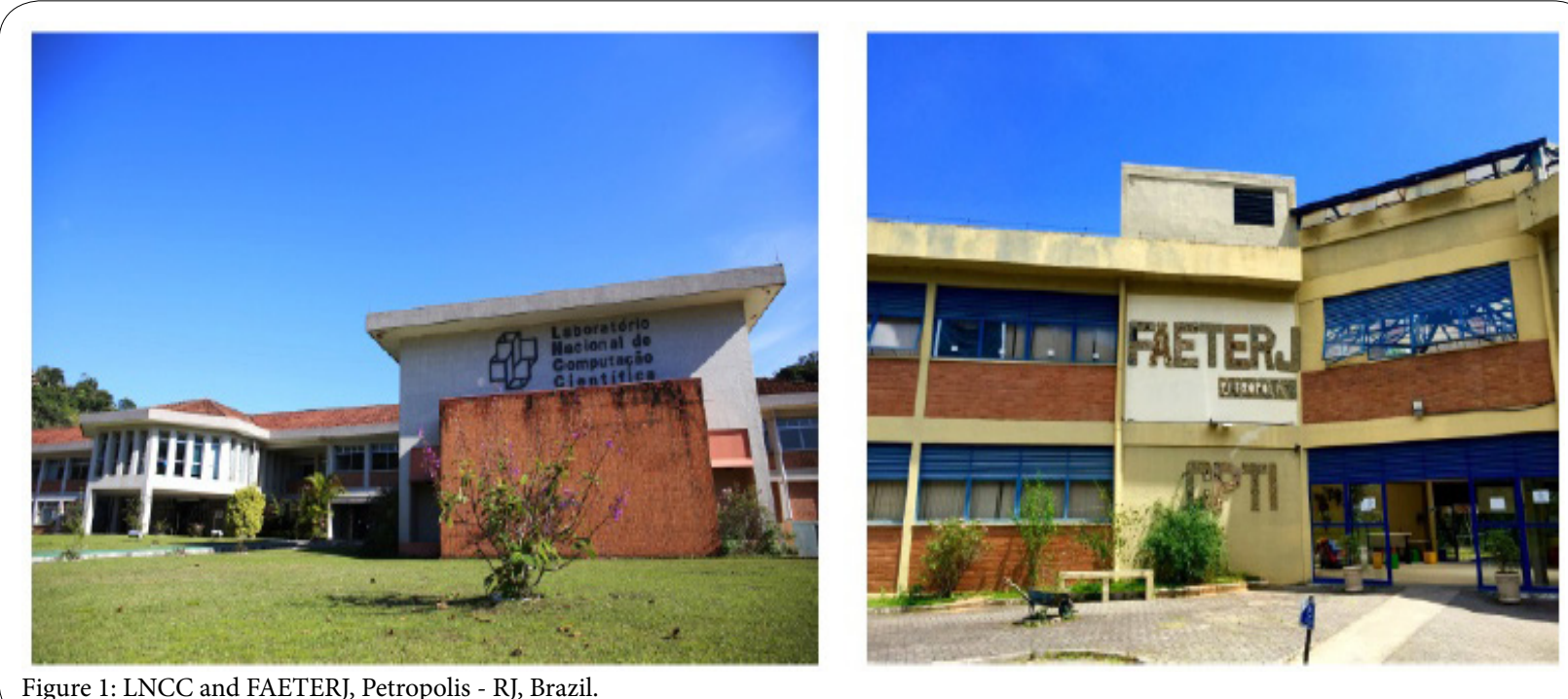

Figure 1: LNCC and FAETERJ, Petropolis - RJ, Brazil. 
To keep the students motivated or interested in the computer graphics itself, I started to show them videos explaining about visual effects in movies, or how some video game was made, and so on. I tried to be aware of what was going on in the entertainment world in order to show them that they are exposed to computer graphics almost every day. It's a wonderful experience to see the expression of surprise when they understand that special effect or discover a curious fact about a game. And by doing this something really powerful started to happen: some students realized that they wanted to work with computer graphics but they didn't know about it before. They even knew how to start. So these students took advantage of the classes to learn more about the computer graphics as a career option. Some of them even started small projects during the class.

This leads me to the last changing: the evaluation method. Watching those particular students having fun and learning so much with their own projects made me realize that this could be a good way to evaluate their progress. So, I decided to not apply theoretical exams. Instead, the students were free to propose a computer graphics project to be presented at the end of the discipline. I used to list some features that should appear in every project in order to guarantee a minimum scope in which I could evaluate them.

This evaluation method has some interesting advantages once I was looking for a productive environment. First of all, letting the students free to propose the final project forces them to think about everything they have learned and how to use it all together to produce a project. Despite that, they have to learn how to create a project, which is a very useful skill regardless of which career they choose to follow. And finally, the freedom to propose any kind of project implies that the student is the only responsible for how far he want to go. Which means that, for those who are not interested in pursue a career in computer graphics they can do some simple project, but the interested ones can challenge themselves and try to create something that motivates them.

\section{Results}

During the period that I was working as a teacher at FAETERJ I taught computer graphics on average to 500 students. Over the years the students themselves gave me feedback about the class. In this way I could understand the benefits achieved through the changes in the classroom. So, in order to quantify the benefits of the proposed teaching methodology presented above, I prepared an online quiz and I sent it to my former students. In this quiz I made 4 statements and I asked them if this was true or false. I received 50 responses and they are shown in Figure 2.

In general, the proposed methodology reached positive results. They show that the students were able to take advantage of the new teaching environment through learning more about programming in general. Besides that, most of them used to think that computer graphics could be something impossible, and they realized that it is not. One of the results that makes me happy is that most of them started to enjoy computer graphics after the class.

Finally, all of the students said that they learned much more by creating a project by their own than having to study for some theoretical exam. This is for me the most important result, because it was the most challenging changing that I decided to adopt. For the perspective of the teacher, it is much more exhaustive and complex to evaluate several different projects. But I noticed over the years that this was a really effective changing. I can tell by experience that the students were more motivated after the adoption of the new methodology. Figure 3 shows some feedback from the students that participated on the quiz.

When I first thought about proposing a new teaching methodology I was aiming to create a classroom environment where the students could feel comfortable and motivated to learn more. I know the reality

"Before attending the computer graphics class/ thought it was impossible to develop a graphical application. but then I realized it was not that difficult"

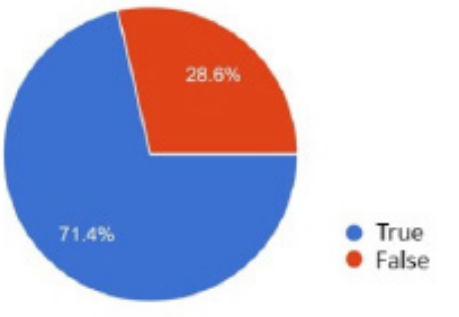

"l learned much more through implementing projects then studying for theoretical exams."

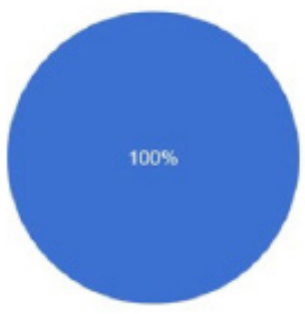

True

- False

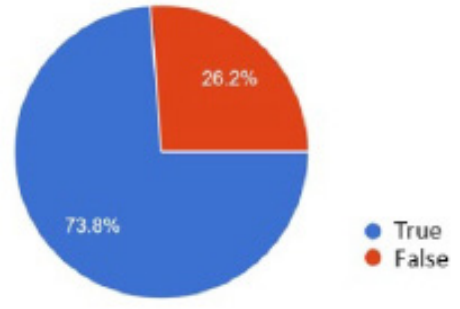

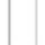

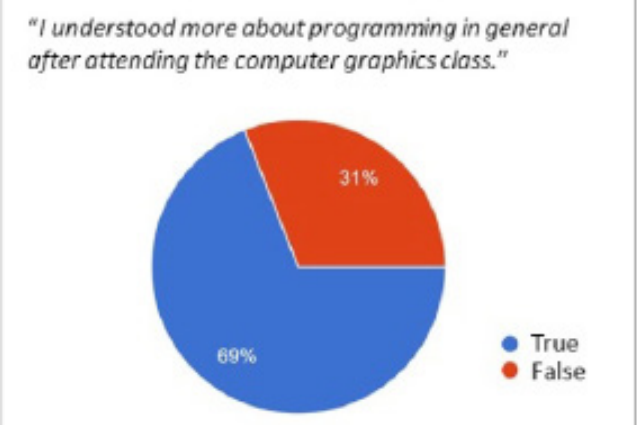

"I had no interesting in computer graphics but after the class / started to enjoy it."
IJCSE, an open access journal Volume 5. 2020. 156 
Citation: Judice SF (2020) Reaching the Impossible: Tales of a Computer Graphics Teacher. Int J Comput Softw Eng 5: 156. doi: https://doi.org/10.15344/2456$4451 / 2020 / 156$

about job opportunities in the city of Petropolis or even in Brazil itself and honestly I never thought that I could see one of my former students working specifically with computer graphics. However, I was surprised by what I consider today the highest result obtained: some students not only work with computer graphics as they had the experience of moving to other countries. Thus, I want to share here some of these success stories but I will let them speaking for themselves. Below we have two stories about former students that are working with computer graphics. And a recent student who is still finishing college and discovered his passion for computer graphics.

\section{Joao Paulo Lacerda}

My name is Joao Paulo Lacerda [5]. Like most 3D artists, I started very early on the traditional drawing, since I was able to hold a pencil in my hands. I remember that my brothers also drew, both are much older than me, we played together and I saw their drawings and I loved them. I remember watching a lot of cartoons and playing video games when I was younger but until then, this universe had not generated much interest until I watched "Jurassic Park" the movie. I remember asking the question, how do I get from here, from the viewer, to the other side of the screen? I started to study digital arts on my own, illustration and 3D. In 2009 I joined FAETERJ, I learned a little more about the technique, how everything works behind the graphics. It was a period of much experimentation and I worked hard and learned a lot, to the point of being recognized by the college colleagues and teachers, then came the opportunity to teach in a free course of animation where I ended up improving my skills a lot. I started working on games and animation projects with friends and then I was hired by Allen Motion [6], a company from the Allen group, where I
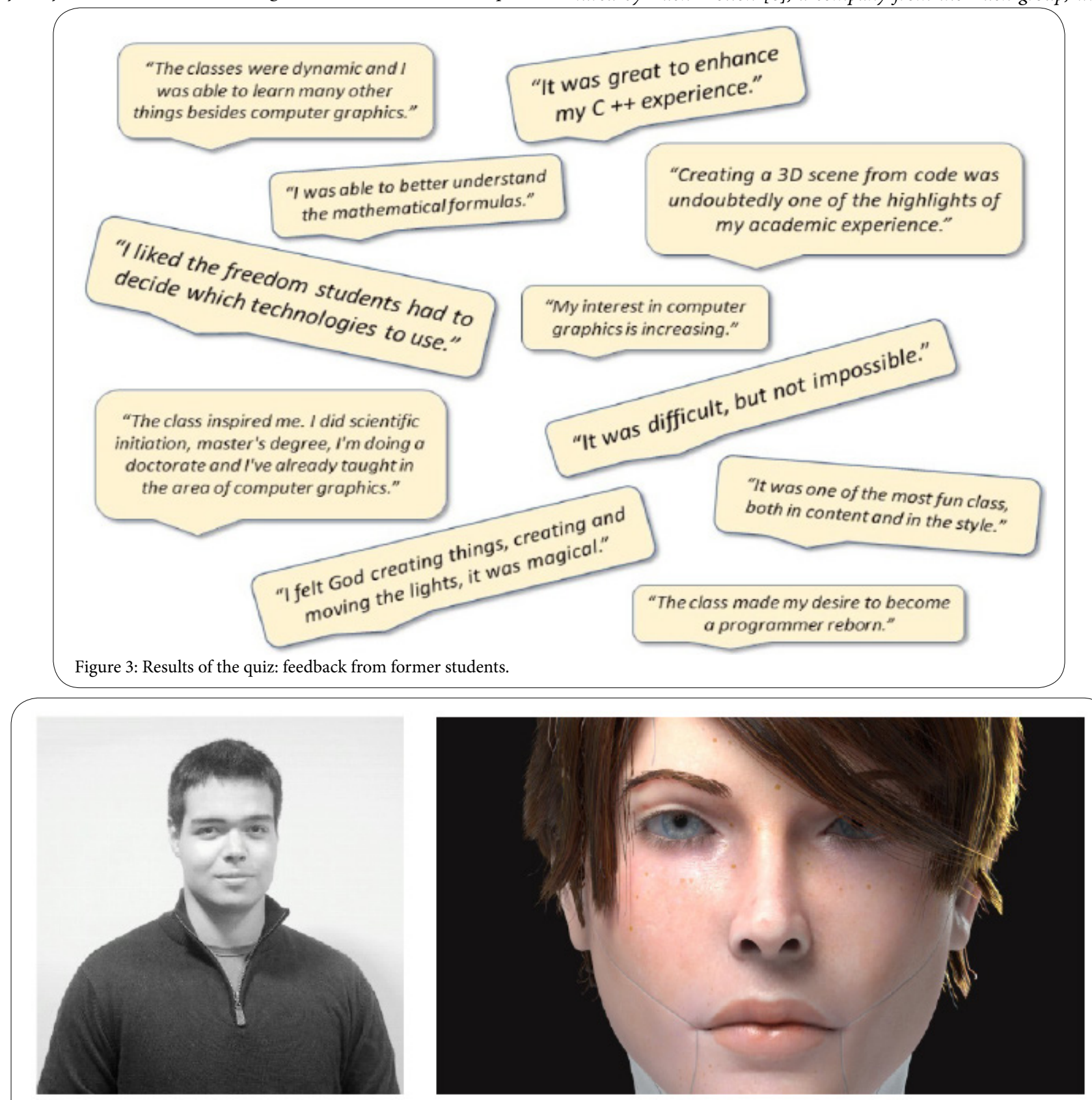

Figure 4: Joao Paulo Lacerda and one of his work. 
Citation: Judice SF (2020) Reaching the Impossible: Tales of a Computer Graphics Teacher. Int J Comput Softw Eng 5: 156. doi: https://doi.org/10.15344/2456$4451 / 2020 / 156$

Page 5 of 6

learned a lot. Then I started my own company with the same friends from college, received an investment and all this happened very fast. As a founding partner of my own company I learned a lot about the market and how it works. The company ran for almost 3 years until the difficulties and challenges became too big and the money was gone. Each of us went his own way. At that point, a little desperate and with little hope I started to work as a freelancer in small projects, which gave me time to update my portfolio, until in early 2016 I was hired by Lithodomos VR [7], a startup initiating a pioneering virtual reality project, recreating archaeological sites around the world for universities, museums and tour guides. In 2017 I was invited to move to Melbourne in Australia, office and headquarters of the company. I worked with them for 14 months until investors decided not to invest any more. The company then suffered without funds and I was sent away along with $90 \%$ of the staff. At the moment, already back to Brazil I am again updating my portfolio and curriculum, this time with an extensive experience in the area. I am preparing for the next journey!

\section{Nicholas Balanda}

My name is Nicholas Balanda [8] and my first contact with computer graphics was in 2009, when I had the opportunity to compete in an animation contest focusing on the environment. I had no experience of animation and was still at school, but a good friend and I took on the challenge and decided to create a stop-motion animation using the limited resources we had available. Although the experience was challenging, the feeling I had when we finished the video was one that undoubtedly shaped my career choices, especially as we actually won the contest! Even though our animation was quite simple, I began to look more intently at moving images and that made me want to learn about more complex forms of animation. I started researching and playing with a few animation programs, such as Pivot [9]. In 2011 worked on a project where the goal was to create an educational game using the Blender Game Engine [10]. I had heard about Blender during the animation contest because the runner-up had produced a $3 D$ animation using that very program, and I had been blown away! Luckily for me he was part of the new project and gave lessons on how to use the engine, so this was an ideal opportunity to learn how to use an advanced computer graphics software. The project was having a few problems and the other developers left, leaving me as the sole developer. I managed to create a version of the game using Blender's game engine, but I soon realized that it wasn't the best software for creating games, so I started searching the best free game engines available. I found Unity $3 D$ [11], a free multiplatform 3D game engine that uses the C\# language. After studying I managed to create a Unity version of the game I had made in Blender and I also made an Android version of it. After this experience, I found a new passion, which was game development, and my studies in the area never stopped. In 2013, I took a Computer Graphics module as part of my undergraduate program and that showed me a lot of different concepts and how things worked at that backend of the programs that I was using. This gave me a much better understanding and a new set of skills that definitely helped me in my upcoming project challenges.

In the following year I had the chance to participate in a Brazilian program called Science without Borders, which allowed me to study Game Development at the University of East London [12] for an entire year. It was a great experience. I learned a new simple game engine called Stencyl [13], 3DS Max [14], a bit of Photoshop [15] and, of course, more about Unity. However, what I enjoyed the most were the group projects, working with others with the same interests as me and that made me more certain than ever that I wanted to work in the gaming industry. When I got back to Brazil, I started a gaming company with a few friends called Hot Potato Games, and we created a few games and published them on Google PlayStore, which was the first time I had actually published my first product, and which was a new learning experience in itself. Aside from the company, I had to finish my Degree and for that I needed a final dissertation, so obviously I made a game: an educational game called Jogo da Forca (a hangman style game). In 2016, I began teaching game development using Unity 3D at a local Tech School, and this was the point at which I realized that I was good at what I did, that I actually had very good experience and that I could pass on my experience to others, all of which brought me joy and confidence in my skills. At the end of 2018, I received a job offer to work in Portugal for a start-up shooting simulator called Easy Aim Simulator [16], where I could show off my Unity and Blender skills. Getting a job in Europe had been a life long dream that was finally realized, proving that all my hard work had been worth it, and it all started with a simple stop motion animation.

\section{Matheus Evangelista}

My name is Matheus Evangelista [17], I grew up in the metropolitan area of Rio de Janeiro, and during my adolescence I have always been
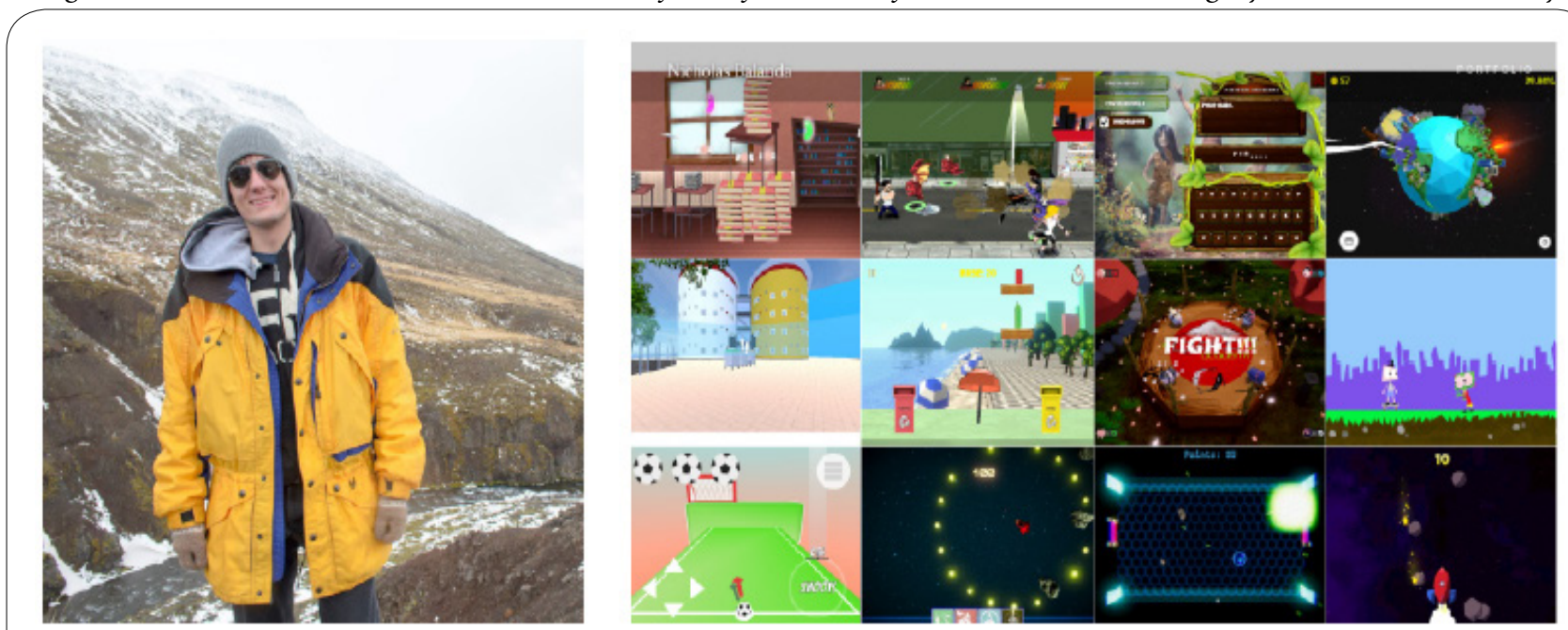

Figure 5: Nicholas Balanda and some of his works. 

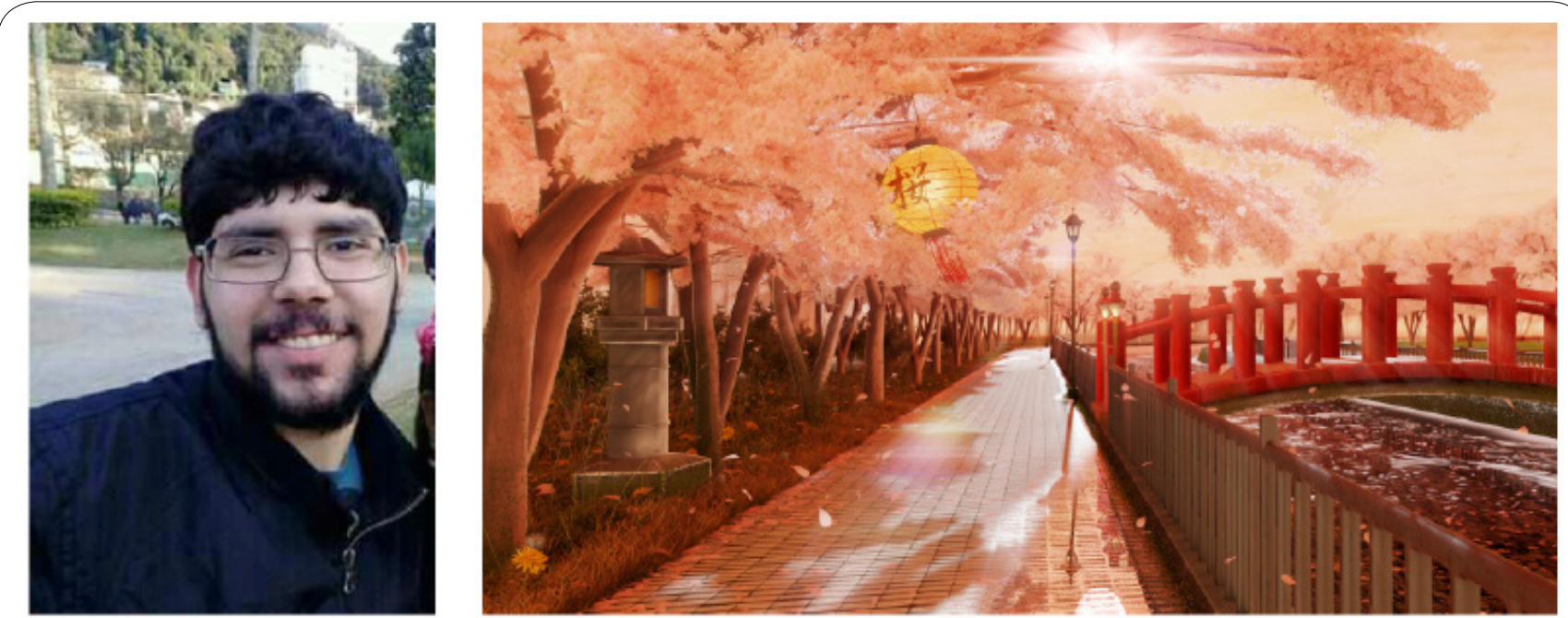

Figure 6: Matheus Evangelista and one of his work.

attracted to movies, games and animations. Until then, I had had no contact with creation or production simply because I was not presented or encouraged enough. After enrolling in the discipline of introduction to computer graphics, taught by Professor Sicilia Judice, I realized that my hobby could be taken more seriously, and that everything I needed to become what I wanted, I already had. Today I have focus, I research and learn on my own, at my pace, envisioning being a 3D Artist and working with games, helping to create what I so admire.

\section{Conclusion}

Before I even became a teacher and a researcher, I was once a confused student trying to understand my role in this world. And as a young person we tend to measure the possibilities according to the examples around us. If you are not a curious person, it is likely that you will follow the path of your parents. In my case no one in my family worked with technology and going to this direction was the same as exploring an entire new world. I am pretty sure that until now they don't truly understand what I do for living. But even so, my family has always supported my decisions.

During college I still doubted much about my ability to work with technology. There were several moments when I thought about giving up. But I think that what kept me strong was more then the technology itself, it was the way teachers motivated me, it was the passion that some of my friends showed openly. Every time I failed they told me to keep going, because is through failure that we achieve knowledge. And that kind of interaction taught me more than any book or class. When I started teaching I was concerned about preparing a good class full of theoretical content but I forgot the human aspect. It took me time and effort to understand how to change and why to do so. Today I can say that it was not only beneficial for students, but also made me evolve a lot as a human being.

Nowadays there are so many career options that one can get lost trying to decide what to do. Due to my experience I believe that college can do much more than provide a degree. It can provide an environment where students can grow, can talk about their fears, can be productive and creative. And I believe that teachers have the main role in all this process. Theoretical exams, grades, evaluations, all this won't matter in the long term. If we are able to motivate the students to try and fail, and try again, if we can teach them how to study by themselves, how to be resilient in their decisions, if we can show them that sometimes pursuing a dream can take a long time but worth it, in my opinion, we are giving them the necessary resources to reach their impossibles.

\section{Acknowledgment}

I want to thank all the students who participated in the research, in particular to Joao Paulo Lacerda, Nicholas Balanda and Matheus Evangelista for contributing with their testimonies. Specially, I would like to thank all the professors and friends that crossed my path and inspired me be the person I am now!

\section{Competing Interests}

The author declare that there is no competing interests regarding the publication of this article.

\section{References}

1. Campos Prefecture.

2. Sicilia Ferreira P. P. Judice.

3. LNCC (National Laboratory of Scientific Computing).

4. FAETERJ (College of Technical Education of the State of Rio de Janeiro).

5. Joao Paulo Lacerda. Freelance 3d artist.

6. Allen Motion

7. Lithodomos VR.

8. Nicholas Balanda.

9. Pivot Animator.

10. Blender.

11. Unity.

12. University of East London.

13. Stencyl.

14. Autodesk.

15. Adobe

16. Easy Aim Simulator.

17. Matheus Evangelista. 